\title{
O som direto e o tuxaua Manoelzinho
}

David Pennington *

\section{Resumo}

Uso e dimensão do som direto no audiovisual, registrados nas filmagens de "Guaraná, olho de gente", de Aurélio Michiles, em Maués-AM.

Palavras-chave: Sateré-Mawé; guaraná; filmagens.

\section{Abstract}

This article deals with the use and the dimension of the direct sound on audiovisuals, that are registred in the filmings of Aurélio Michile’s documentary "Guaraná, olho de gente", in Maués-Am.

Keywords: Sateré-Mawé indians; guaraná fruit; filmings.

\section{Rio Marau}

Chegamos a Maués-AM, 1982, a terra do guaraná, a terra dos Sateré-Mawé. Nosso objetivo era fazer um filme em $16 \mathrm{~mm}$, sobre o guaraná, mas os recursos não chegaram, e o Aurélio Michilles resolveu fazer em vídeo, mesmo. Fazer em vídeo, naquela época, significava fazer um trabalho com impacto e visibilidade menor, pois o vídeo tinha uma qualidade decididamente inferior à película e, sobretudo, não alcançava os festivais. Não é como agora, em que, a partir do vídeo digital, pode-se fazer um filme cinematográfico para projetar numa sala de cinema, circular em festivais etc. Nas antigas câmaras de vídeo, com gravador em separado, registra-se a imagem e o som na mesma fita. Mas já tendo clareza da necessidade de um som de qualidade, levamos adicionalmente um gravador Nagra, para as gravações de som ambiente, cantorias etc., além de um conjunto (pequeno) de microfones de qualidade.

Embarcamos numa voadeira, subindo o rio Marau em direção à aldeia Sateré.

\footnotetext{
* Doutor em História (UnB e Liverpool Univ.). Professor do Departamento de Audiovisuais e Publicidade da Faculdade de Comunicação da UnB. E-mail: dpgton@gmail.com 


\section{Atitude}

Embarcados, estamos com os laços cortados com a civilização, literalmente. Se alguma coisa faltou, não há como retornar para corrigir o esquecimento. Somos uma caravela em alto-mar. Daí a necessidade de uma atitude em relação aos equipamentos de registro. "Em terra", antes de partir, conferir e reconferir. Testar, e testar de novo o equipamento antes de sair. Verificar cada item. Pilhas novas, baterias carregadas. Fitas para as gravações. Integridade dos cabos de conexão. Verificar se os equipamentos estão efetivamente gravando imagens e som. Ferramentas básicas e, é claro, os objetos pessoais, sempre o mínimo.

Em relação ao instrumental, ocorre uma quase antropomorfia como nos seringais de outrora, em que o homem isolado dava nomes próprios ao terçado, à canoa, à espingarda. Cada componente merece um nível de respeito, não pelo que é, quanto pode custar (e alguns itens custam muito caro), mas pelo potencial que representam na captação de imagens e sons, geradores de discursos passíveis de transformar a realidade (este microfone nunca me deixou na mão!). Assim, surge até uma espécie de "amizade" com cabos, microfones, gravadores.

\section{Contexto}

O ambiente na Amazônia, com umidade em torno de $90 \%$, exige cuidados na embalagem e transporte de equipamento. Por um lado, esta "embalagem" deve permitir solicitação e uso imediato do equipamento; por outro lado, mantê-lo protegido das adversidades do meio ambiente. São duas situações contraditórias. A não ser o equipamento especialmente preparado para uso militar (que nunca cheguei a fazer uso), os equipamentos correntes são moderadamente resistentes às condições extremas, tais como desertos, Ártico, Amazônia. Portanto, um preciosismo é necessário na manipulação de equipamento audiovisual, mormente nos dias de hoje, em que o equipamento tem uma qualidade "descartável", já que o preço relativamente acessível é associado a uma obsolescência tecnológica programada. Cuidando bem, o equipamento dura anos.

\section{Registro sonoro}

Edison inventou o fonógrafo ou gramofone, primeiro dispositivo que registrou o som com posterior reprodução. Era uma agulha que registrava em uma

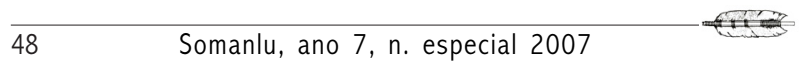



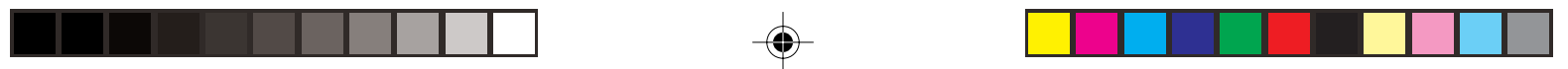

David Pennington

superfície metálica (folha de estanho) sobre um cilindro de aço sulcos a partir de uma agulha fixada num diafragma. Movimentado pelas ondas sonoras, a reprodução era semelhante, a agulha passando pelos sulcos fazia a membrana vibrar, reproduzia o som. ${ }^{1}$

\section{O Porantim do tuxaua}

O tuxaua, como em transe, incorpora seus antepassados. Um lado do remo - o registro da história dos Sateré - passando os dedos pelos sulcos do "lado A" do remo... O tuxaua torna-se a voz dos avoengos, conta a história dos Sateré desde o alvorecer dos tempos... O Porantim-osso-astronave-kubrickiano. Na giria, ${ }^{2}$ o som de uma litania, um tom trêmulo vindo do passado. Quantas caçadas, guerras e mortos, amores e lugares passados! Os bichos-do-fundo emergindo novamente. Os mortos revividos falando por seu médium. Edison compreenderia esse fonógrafo?

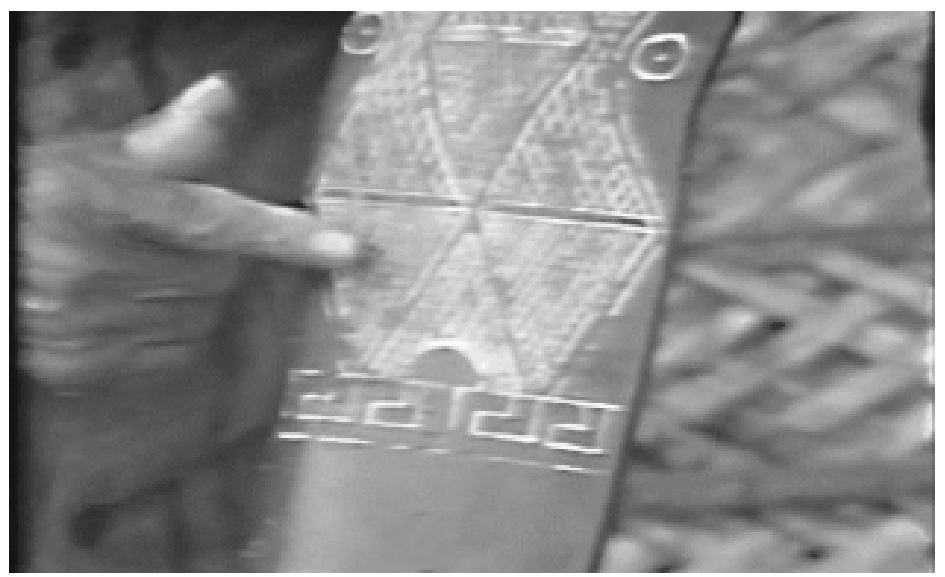

O "lado B" do Porantim... a chegada dos homens brancos, os primeiros embates, grandes massacres, o genocídio de milhões de índios vivendo ao longo dos rios. As doenças, mentiras, estupros e pólvora. A voz que fala, um tremor diferente. A Voz do Dono - da terra! O Porantim - Meu Deus, isto fala! Um gramofone-telefone-tecno-ilógico e antropo-lógico! 

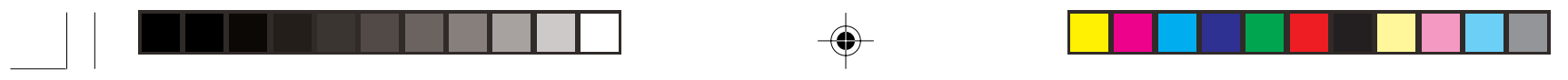

0 som direto e o tuxaua Manoelzinho

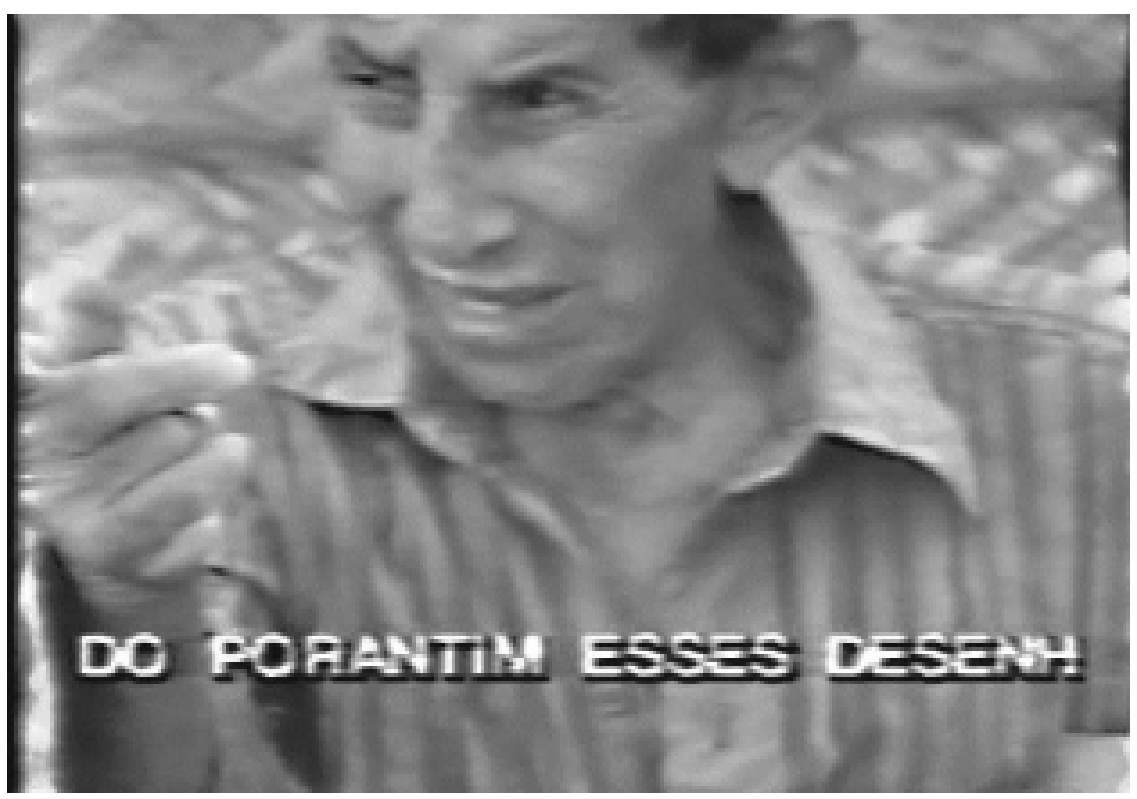

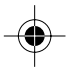

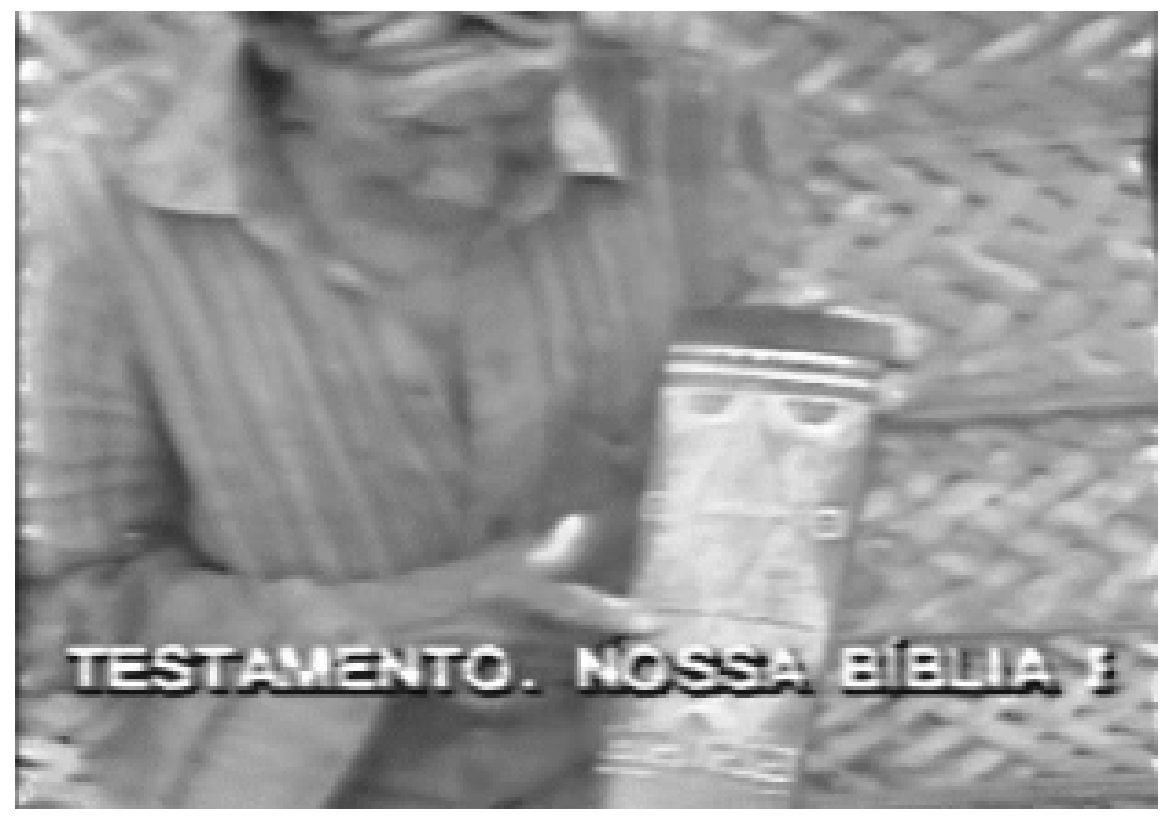
$f$ 

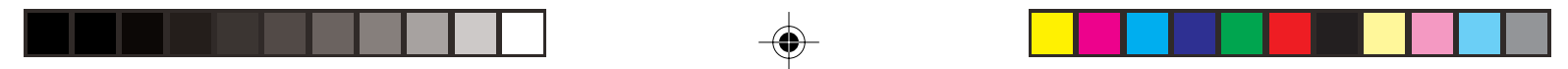

David Pennington

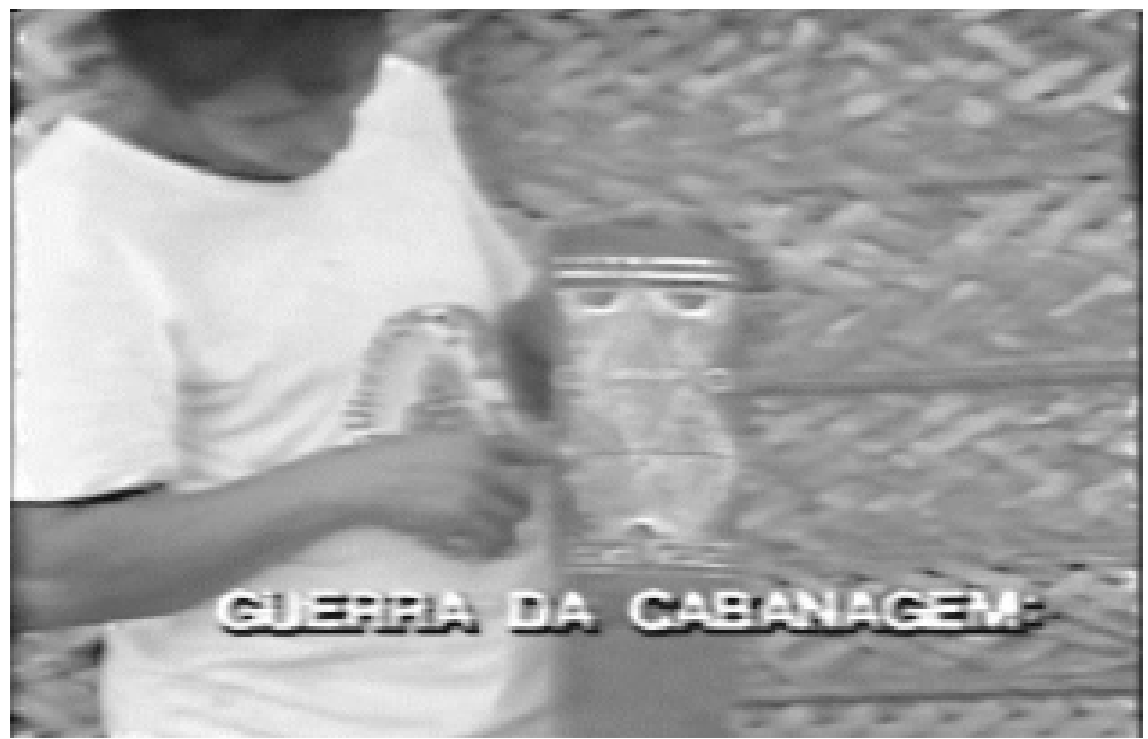

Imagens extraídas dos vídeos "Guaraná, olho de gente" e "Sangue da terra", de Aurélio

Michiles, 1982.

O velho tuxaua, passando os dedos pelos sulcos gravados no Porantim, reproduzia a história de seu povo. Um gramofone tecno-ilógico e antropo-lógico!

Muito mais que o som, a história contada à luz das fogueiras, nas noites aconchegantes, dos velhos para os meninos, na passagem dos séculos, gravada no Porantim. Manoelzinho recusou muito dinheiro de um turista pelo Porantim.

\section{Som direto}

Eu registrando essa voz, meu único medo: ser traído pela técnica, que nestes equipamentos comparativamente tão precários não seja fixado o som dessa cena incrível, acontecendo diante dos meus olhos. Um respeito imenso diante dos ecos do passado, de um passado remoto sedimentado num remo, mas que só pode ser lido por um único equipamento sofisticado no mundo, as mãos e a memória atávica de um velhinho Sateré.

Som direto é o conhecimento técnico aliado à reflexão. Pensar a situação aliado à correta técnica. A correta técnica exige um entendimento dos fenômenos, única forma, na minha visão, para a compreensão plena dos processos envolvidos. ${ }^{3}$ 


\section{Oportunidade}

O sentimento de oportunidade. No documentário, o sentimento de oportunidade é essencial. As coisas acontecem com uma dinâmica própria, tem-se que estar atento, uma leseira e perde-se a oportunidade. E nada se repete num documentário, não existe voltar lá amanhã, é tiro e queda.

\section{O microfone}

O microfone é o instrumento fundamental. Pesca som. O som é muito elusivo, fugidio. As vozes, prolongamentos dos entes, vibram no ar. Vozes se empolgam, se retraem. Tem-se que perceber a voz e acompanhá-la. Há vozes fortes, com variações de volume abruptas. Vozes tranqüilas, com pouca variação de volume. Vozes em baixo volume. Vozes cansadas, que já viveram muito. E as vozes das crianças, descobrindo o mundo.

Cada microfone "ouve" de um jeito diferente. E nós que trabalhamos com o som, temos que ouvir o microfone! Ouvir o que ele ouve, o jeito com que ele ouve. Cada microfone ouve de forma diferente. Uns ouvem melhor as baixas freqüências, os graves. Outros, as freqüências mais agudas. E tem aqueles que ouvem mal. Têm que ser descartados - a não ser que sejam a única opção.

As vozes das crianças são dotadas de freqüências altas e, como transientes, mudam de volume subitamente. A maioria das mulheres, também, mas na idade adulta controlam os transientes. Porém, as emoções traem a todos nós, denunciadas pela voz. As vozes cansadas são as mais difíceis de registro. Deficientes, em geral, de altas freqüências, requerem cuidados a mais.

Esta "poesia do som" se traduz em duas vertentes de ação: ouvir o mundo é preciosismo técnico. Como afirmava Humberto Mauro, "cinema é cachoeira". E o som é uma cachoeira constante, ferindo o ouvido. Que não tem pálpebras. Vivemos rodeados de um campo sonoro, que modela psico-fisiologicamente uma de nossas mais importantes percepções do mundo. E que na memória cria marcos, trazendo alegrias e saudades, quando ouvimos aqueles sons replicados nos produtos audiovisuais. Quando registramos o som, estamos documentando um espaço-tempo.

Quando a câmara registra uma imagem, o canal de som registra um campo sonoro. A câmara seleciona, exclui tudo, exceto o que se vê no quadro. O som,

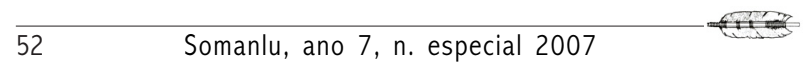


David Pennington

porém, tem um registro mais amplo, a única possibilidade de seleção é pelo posicionamento do microfone - sempre o mais próximo possível da fonte sonora, da voz.

\section{Ruídos de manipulação}

$\mathrm{O}$ microfone reage também às vibrações das mãos, aos ruídos de manipulação. Uma qualidade do técnico de som é a delicadeza direcionada no manejo dos microfones, para o que é essencial o uso dos auriculares, os "fones de ouvido", sem os quais não temos noção alguma do que está sendo registrado. Um recurso universal é o "boom" ("la perche", para os franceses), uma vara ${ }^{4}$ sobre a qual é fixado o microfone, o que permite localizá-lo da melhor forma, rapidamente, e sem macular o quadro. A fixação do microfone é feita com uma "suspensão elástica", que reduz, de pouco ao desejável, dependendo da suspensão, os ruídos de manipulação. Estes equipamentos podem ser adquiridos no mercado, mas é também possível um improviso de qualidade.

Os fios e cabos que interligam o microfone à câmara também merecem reparo. Têm que estar em bom estado, com suas "pontas" ou conectores em boas condições de uso (sem falta de parafusos, soldas perfeitas). Nisso é necessário que sejam guardados com os cuidados adequados: enrolados em curva amiga ( 25 a 30 cm de diâmetro), limpos com um pano embebido em álcool após um uso prolongado (uma semana, ou menos, dependendo das circunstâncias).

\section{Antecipação}

Antecipação é outro talento que se desenvolve. É um "faro psicólogo", entendendo o sujeito, suas reações diante dos fatos que se alevantam. Uns emotivos, o volume de voz varia desvairadamente, são um problema, afastar rápida e criteriosamente o microfone, destarte evitando a sobrecarga de sinal, e logo trazê-lo de volta para as emissões sonoras mais contidas e o operador de som antecipa a eclosão desta carga emocional... Outros são bem mais previsíveis. Mas, cuidado, que a câmara pode, sem aviso, mudar o seu enfoque para um acontecimento imprevisto, o som, atento, não abandona seu par. 


\section{Lautério}

Lautério, olho-de-capivara, enfoca o mundo de vários ângulos ao mesmo tempo. Sabe as curas do corpo e da alma. Fala mansa, homem bem humorado. Acionando um pequeno chocalho conclama as forças de seu universo. O chocalho do pajé parece o microfone que eu uso. Meu microfone é constituído de uma membrana plástica extremamente fina, revestido com ouro, um plástico desenvolvido após a Segunda Guerra Mundial. O som atingindo esta membrana sensível dá-lhe vida e movimento, que é transformado em energia elétrica, o "áudio". Parece bem mais complicado: tudo isto está acondicionado numa cápsula metálica, tem um amplificador e uma fonte de alimentação, leva pilha. Esta sofisticada leitura deste dispositivo permite que eu "entenda-o". O áudio produzido é registrado, seja num gravador de áudio ou numa câmara de vídeo. Para a utilização deste microfone são necessários cabos (fiação) de áudio, "fones de ouvido" (auriculares) e as devidas interligações com o equipamento mãe (onde será registrado o áudio). Enfim, um ritual eletro-mecânico social. O chocalho do pajé é feito de uma cabaça fincada numa vareta, dentro do qual há algumas sementes. Parece simples. Mas o microfone não tem o DNA que as sementes do chocalho têm... O que resulta disso é muito ambíguo. O vídeo "Sangue da terra", feito paralelamente ao "Guaraná, olho de gente", teve um papel decisivo na demarcação das terras Sateré, que estavam sendo exploradas ilegalmente pela Elf-Acquitane. Um som e imagem contra a alienação.

Lautério, no meio do guaranazal, começa uma litania. Palavras numa língua desconhecida. Me chama pra perto. O chocalho, uma cabaça preta com desenhos riscados e preenchidos com tabatinga branca. Adornado com a pena de algum pássaro. Nesta liturgia xamânica ele me reza. E olha que já passei por muitas situações reais de perigo, aqui na Amazônia! Nunca uma malária, febre amarela, ferimentos ou diarréias. Muitas expedições, quase sempre precárias, muitos documentários, sempre incólume... O som de uma ladainha ancestral contra os perigos do mundo...

\section{O som no audiovisual}

Falemos sobre o som. Manifestação perceptiva derivada da propagação mecânica de perturbações em meio elástico (ar) que alcançam nossos ouvidos... Som direto é um conceito. Vem da era em que o único registro audiovisual efetivo era o cinema, e que não registrava o som em sincronismo com a imagem. O som era, na

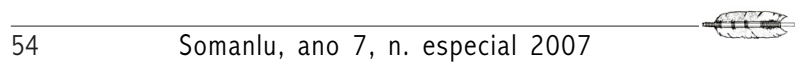


realidade, aposto. E utilização da narração era essencial, uma voz exterior, estranha, descrevendo acontecimentos.

Som direto é um termo que surge no momento em que o registro de som, no cinema, é viabilizado como síncrono com a imagem. Antes de 1930, o cinema é conhecido como "cinema mudo", ou silencioso; mas isso é um termo vago, já que os filmes sempre tiveram uma trilha sonora, fosse por meio de discos fonográficos, pianista contratado, uma troupe que acompanha o filme de cidade em cidade, ou, nas produções mais ambiciosas, uma peça especialmente composta, com partitura e as necessárias instruções (Ver GOMES, 1980; COSTA, 1996, p.84-86). Fato é que Edison, o inventor do fonógrafo, já experimentara por volta de 1911 sincronizar som e imagem entre o fonógrafo e o cinematógrafo (NEALE, 1985). Em torno de 1925, noticiários no cinema apresentavam um sincronismo precário entre discos e rolos de filmes projetados no cinema, com os sistemas movietone ou vitafone. A partir de 1929-30 o sistema de som ótico sobre a película é adotado nos Estados Unidos, na Alemanha e outros países da Europa e o som síncrono passou a ser o padrão adotado internacionalmente. Na prática, significava que na película ou filme a ser projetado na sala de cinema, ao lado das imagens, havia uma "banda" ou "trilha" ótica, que continha as informações de som passíveis de decodificação pelo projetor. Assim, o som e a imagem estavam precisamente em sincronismo.

Porém, durante a feitura de um filme, o registro sonoro era feito em película separada, em registro com o projetor, durante a filmagem. Isto tornava o processo absolutamente dependente das grandes estruturas de produção, os estúdios de cinema. Após a Segunda Guerra Mundial (1938-45), o desenvolvimento da fita magnética de gravação de som faz disseminar, simultaneamente com câmaras de filmagem mais leves, gravadores de alta qualidade para o registro do som direto, ou seja, no ato da filmagem, em qualquer lugar. ${ }^{5}$ Este processo, revolucionário, ajuda a alavancar o ideário de novos cineastas que, fugindo do estratificado sistema de estúdio, vão para a rua fazer seus filmes. Daí o Neo-Realismo italiano, a Nouvelle Vague na França, o Cinema Novo no Brasil. Até que o acesso a estes equipamentos se torne amplo, muitos trabalhos ainda fazem uso dos métodos anteriores: os primeiros filmes do Cinema Novo brasileiro tiveram seu som gravado em gravadores de filme, ou seja, em película cinematográfica.

No processo de produção de um filme sonoro há muitas etapas a serem vencidas ${ }^{6}:$ o registro sonoro síncrono com a imagem (basicamente falas), o registro

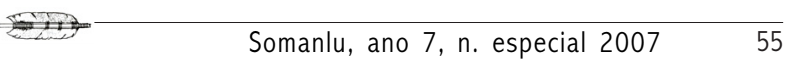


dos sons presentes no momento e locais das filmagens, o registro do "som ambiente" ("room tone", "tom de sala" em inglês), que caracteriza de forma psicofísica o local. Todos esses registros formam um repertório essencial para o montador ou editor do filme e serão, ademais, complementados por música, locuções (narrador, "voiceover") e outros sons tidos como essenciais para o entendimento do filme. Esse registro das falas simultâneo à ação, e em sincronismo, é uma verdadeira vitória da tecnologia do registro sonoro. A seguir, os sons registrados, começando pelas falas, são regravados para um novo suporte, o "magnético perfurado", que é suporte de película 16 ou $35 \mathrm{~mm}$, revestido com material para gravação magnética. Posteriormente (ou à medida da demanda) trechos com som ambiente são regravados em perfurado magnético. Nesta etapa inicia-se a montagem: trechos de película com a imagem são confrontados com os trechos de magnético perfurado, buscando-se o sincronismo, no caso das falas, e o assincronismo construtivo da narrativa sonora, no caso dos demais fragmentos sonoros. Esta "narrativa sonora" hoje toma uma dimensão muito significativa na elaboração de um filme cinematográfico.

$\mathrm{Na}$ montagem convencional o aspecto braçal da atividade não pode ser subestimado. Enfim, após árduo trabalho temos a imagem montada e, associada a esta, um conjunto de rolos de magnético perfurado (as "bandas" de som) contendo as falas sincronizadas, os sons do ambiente, ruídos selecionados, efeitos sonoros (particularmente em filmes de ficção), narrações etc. O próximo passo é o laboratório de mixagem, serviço contratado, onde todas estas bandas serão misturadas em proporções adequadas, criando-se então a trilha sonora. Finalmente, do rolo de imagem proveniente da montagem contrata-se a montagem do negativo; da banda de som "mixada" (misturada), contrata-se a gravação do negativo de som; e a partir do negativo de imagem montado e do negativo de som contratam-se as cópias do filme para projeção. Atualmente, a maior parte deste trabalho braçal é realizada em ambiente digital, operando um computador, sem a necessidade de manipular trechos de película cinematográfica ou magnético perfurado, e muito menos as intermináveis emendas com fita adesiva transparente especial.

\section{A dimensão sonora no audiovisual}

Desde a disseminação do cinema sonoro em 1930, até os anos 80, não houve um desenvolvimento efetivo no sistema utilizado na projeção de filmes, de

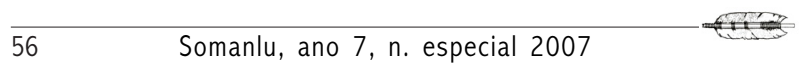


forma ampla, com algumas exceções. Muito embora a estética sonora sofresse desenvolvimento, este tinha no patamar tecnológico da qualidade de gravação e, sobretudo, na qualidade de reprodução nas salas de cinema, um fator limitador muito evidente. A partir dos anos 80 , porém, a introdução do sistema "Dolby Stereo", com redução de ruído e expansão da faixa de freqüências de áudio, e com som estereofônico, houve um avanço significativo da estética sonora no cinema, particularmente nos filmes-espetáculo de Hollywood. Ainda assim, com a chegada dos sistemas multicanal em ambiente digital, tais como o "Dolby Digital", em 1990, apresentando seis canais de som com ampla gama de freqüências de áudio e um canal dedicado às baixas freqüências, as salas de projeção não correspondiam às necessidades da reprodução sonora de tais sistemas. Durante a década de 90, em substituição ao sistema obsoleto VHS, vimos a larga introdução do sistema de discos DVD, estes últimos apresentando o sistema Dolby digital como padrão. Ao mesmo tempo, os equipamentos de reprodução de vídeo doméstico começaram a apresentar o "home theater" (cinema em casa), capaz de reproduzir o sistema multicanal a preços bem acessíveis. Estes novos ambientes de apreciação cinematográfica criaram um campo novo na estética do som do cinema, com o surgimento de novas profissões, tais como o "sound designer", o profissional que faz, digamos assim, a direção de arte do som de um filme. ${ }^{7}$

$\mathrm{O}$ ambiente digital ainda nos brinda com câmaras digitais pequenas, que permitem, inclusive, gerar material, que depois de editado em computador é factível de ser transformado até em filme ou película cinematográfica para projeção em salas de cinema, ou discos DVD para disseminação em ambiente digital.

A boa notícia é que o som direto nunca esteve tão vivo e adquiriu uma importância extrema na produção de um filme, quer seja documentário, quer seja ficção.

No ambiente digital, o som é gravado na mesma fita onde as imagens são gravadas. As preocupações com a captação, porém, seguem as mesmas regras desde o início do registro sonoro no cinema, e mais precisamente desde quando, nos anos 60 , surgiram os gravadores mais leves e ágeis e, sobretudo, os microfones modernos tipo condensador.

As principais preocupações de quem vai captar o som são:

* Familiaridade com o equipamento;

* Seleção de microfones para a situação em lide;

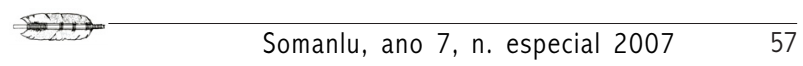


* Controle dos volumes de gravação;

* Localização adequada do microfone - o mais perto possível da fonte sonora;

* Atenção com ruídos, ou sons indesejáveis, e como controlá-los;

* Atenção com a estética de câmara e movimentos de câmara;

* Controle diário do equipamento, limpeza de seus elementos, condições de cabos, pilhas e baterias;

* Capacitação para pequenos reparos;

* Criatividade para resolver problemas que surgem.

A técnica não é difícil de ser aprendida, exige, porém, disciplina e observação. Aos poucos, informações e textos sobre som direto vão se disseminando. ${ }^{8}$

Para aprender a gravar som direto, conheça o equipamento, experimente muito, e sobretudo, ouça os resultados de sua experimentação num equipamento de som com volume adequado, nem baixo, nem alto demais. Um bom televisor é útil para esse monitoramento. Ouça várias vezes, até esse som gravado revelar suas nuances.

\section{Epílogo}

Participar da produção desses dois trabalhos, dirigidos pelo meu amigo e compadre Aurélio Michiles, foi extremamente gratificante, assim como o foi alguns dias na aldeia convivendo com os Sateré. A aprendizagem com o tuxaua Manoelzinho, e além de contar histórias gravadas no Porantim, me ensinou como arquitetar uma casa arejada, mesmo sob um sol inclemente. Lautério, com seus poderes xamânicos, passou-me insuperável confiança na vida.

"Guaraná, olho de gente" nos mostra como o guaraná é produzido e consumido ritualmente, uma atividade em que os papéis dos homens e das mulheres são claramente definidos e com significados específicos. "Sangue da terra" mostra a luta dos Sateré-Mawé na defesa de seu território, e como documento contribuiu decisivamente nessa luta.

\section{Notas}

1 A primeira gravação de Thomas Edison pode ser encontrada em http:// www.gutenberg.org/etext/10137

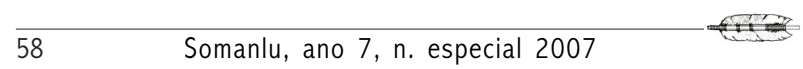


David Pennington

2 “Gíria”, língua Sateré.

${ }^{3}$ Ver: http://www.geocities.com/prodavid/COMO_GRAVAR_SD.html

${ }^{4}$ Ver conjuntos de boom e microfones em: http://www.bhphotovideo.com/c/ product/422108 REG/Sennheiser Ultimate_Shotgun_Microphone_Kit.html

${ }^{5}$ Embora hoje obsoleto, o Nagra foi o padrão da indústria cinematográfica mundial de 1960 até os meados dos anos 90: http:/ /www.nagraaudio.com/pro/index.php.

${ }^{6}$ Este texto faz considerações sobre a produção cinematográfica: http:// www.escoladarcyribeiro.org.br/media/goulart.pdf.

${ }^{7}$ Ver: http://www.geocities.com/prodavid/PLAYGR.html

${ }^{8}$ Ver: http://www.cybercollege.com/indexall.htm - "Produção de TV em Português", também: http://www.urbanfox.tv/workbooks/sonypd150/ (Este é em inglês).

\section{Referências}

COSTA, Selda Vale da (1996). Eldorado das ilusões. Cinema e sociedade: Manaus (1897 - 1935). Edua.

GOMES, Paulo Emílio Salles (1980). Panorama do cinema brasileiro: 1896/1966. In GOMES, Paulo Emílio Salles. Cimema: trajetória no subdesenvolvimento. São Paulo: Paz e Terra.

NEALE, Steve (1985). Cinema and technology. Bloomington: Indiana University Press. Guaraná, olho de gente. Dir.: Aurélio Michiles. Vídeo, cor, 40min., 1982. Prod.: Cinevídeo Céuvagem.

Sangue da terra. Dir.: Aurélio Michiles. Vídeo, cor, 35min., 1983. Prod.: Cinevídeo Céuvagem.

Sobre suporte elástico: http://www.sabrasom.com.br: 